\title{
Modulation of Oxidative Stress by 17 $\beta$-Estradiol and Genistein in Human Hepatic Cell Lines In Vitro
}

\author{
Daniela Surico ${ }^{a}$ Alfredo Ercolia Serena Farruggio ${ }^{b}$ Giulia Raina $^{b}$ Davide Filippini ${ }^{b}$ \\ David Mary ${ }^{b}$ Rosalba Minisinic Nicola Surico ${ }^{a}$ Mario Pirisic Elena Grossinib \\ ${ }^{a}$ Gynecologic Unit; ${ }^{b}$ Lab. Physiology/Experimental Surgery; ' Clinical Medical Unit, Dept. of Translational \\ Medicine, University East Piedmont "A. Avogadro", Azienda Ospedaliera Universitaria Maggiore della \\ Carità, Novara, Italy
}

\section{Key Words}

Cell viability • Estrogenic receptors $\bullet$ Mitochondria • Peroxidation

\begin{abstract}
Background/Aims: estrogens and phytoestrogens exert hepatoprotection through mechanisms not clearly examined yet. Here, we investigated the protective effects exerted by $17 \beta$-estradiol and genistein against oxidative stress in hepatocytes and hepatic stellate cells (HSCs) and the involvement of specific receptors and the intracellular signalling. Methods: Huh7.5 and LX-2, alone or in co-culture with Huh7.5, were treated with $17 \beta$-estradiol and genistein alone or in the presence of menadione and of estrogen receptors (ERs) and $G$ protein-coupled-estrogenic-receptors (GPER) blockers. Cell viability, mitochondrial membrane potential and oxidant/antioxidant system were measured by specific kits. Western Blot was used for the analysis of Akt and p38-mitogen-activated-protein kinases (MAPK) activation and $\alpha$-smooth-muscle actin expression. Results: In Huh7.5, 17 $\beta$-estradiol and genistein prevented the effects of peroxidation by modulating Akt and p38MAPK activation. Similar antioxidant and protective findings were obtained in LX-2 of co-culture experiments, only. ERs and GPER blockers were able to prevent the effects of $17 \beta$-estradiol and genistein. Conclusion: In Huh7.5 and $L X-2,17 \beta$-estradiol and genistein counteract the effects of peroxidation through the involvement of ERs and GPER and by an intracellular signalling related to Akt and p38MAPK. As concerning $L X-2$, paracrine factors released by Huh7.5 play a key role in protection against oxidative stress.

\section{Introduction}

Oxidative stress is a common pathogenic factor in most liver diseases, including chronic hepatitis $\mathrm{C}$ virus (HCV) infection, as well as alcoholic and non-alcoholic fatty liver disease [1-3]. Parenchymal cells, mainly represented by hepatocytes, are primarily subjected to

Prof. Elena Grossini

KARGER
Lab. Physiology and Experimental Surgery, Dept. Translational Medicine, University East Piedmont, via Solaroli 17, I-28100 Novara (Italy)

Tel.+390321660526, Fax +3903213733537, E-Mail elena.grossini@med.uniupo.it 


\section{Cellular Physiology Cell Physiol Biochem 2017;42:1051-1062 \\ \begin{tabular}{l|l} 
DOI: 10.1159/000478752 & a 2017 The Author(s). Published by S. Karger AG, Basel \\
www.karger.com/cpb
\end{tabular}}

Surico et al.: Cytoprotection Exerted by Estrogens and Phytoestrogens

oxidative stress and are able to induce injury in other non-parenchymal cells such as hepatic stellate cells (HSCs) and endothelial cells, which are very sensitive to oxidative stress-related molecules. In particular, HSCs play major roles in case of HCV-related liver damage, since in this condition their phenotype turns from being that typical of a quiescent state into an activated myofibroblastic one, which is characterized by high expression of $\alpha$-smooth muscle actin (a-SMA). In this activated state, HSCs in turn produce growth factors and cytokines which play a key role in the regulation of hepatocytes growth and the development of inflammatory fibrotic liver response [2].

Thus, the cross talk between hepatocytes and HSCs represents a trigger modulator of liver injury perpetuation. As such, it could be considered as a key target of treatments potentially useful to counteract the entire process, which could be involved in the onset of acute/chronic liver disease.

Previous studies have demonstrated that estrogens can exert a number of liver-related benefits among which inhibition of proliferation and fibrogenesis $[2,4,5]$. Those effects could be involved in the different evolution of HCV infection found in women in comparison with men [4,6] and in relation to menopausal state [7]. Also the phytoestrogen genistein, which is the main isoflavone found in soy and is known to be a tyrosine kinase inhibitor, has been proven to act as antioxidant, anti-inflammatory and antifibrotic agent in the liver [8].

Regarding mechanisms of action, nuclear and membrane associated estrogen receptors (ERs) and membrane-bound receptors, including G protein-coupled estrogenic receptors (GPER) could trigger the intracellular signalling cascade response. The downstream pathway activated by the interaction of estrogens and phytoestrogens with those receptors could lead, among other results, to p38 mitogen activated protein kinases (MAPK) $[2,9,10]$ and Akt/phosphatase and tensin homolog activation [10-12].

Thus, the aim of the present study was to compare the protective effects exerted by $17 \beta$ estradiol and genistein against oxidative stress in both hepatocytes and HSCs and to examine the involvement of mechanisms related to ERs/GPER-downstream signaling and mitochondrial function. Furthermore, the crosstalk between those cell types was investigated to analyze hepatocyte-induced myofibroblast transformation of HSCs.

\section{Materials and Methods}

\section{Culture of Huh7.5 and $L X-2$}

Huh7.5 (male immortalized human hepatocarcinoma cell line) and LX-2 (HSCs; male immortalized human hepatic stellate cell line), were maintained in Dulbecco's modified Eagle's medium (DMEM; Sigma, Milan, Italy) supplemented with 10\% fetal bovine serum (FBS; Euroclone, Pero, Milan, Italy), 2 mM L-glutamine (Sigma), $1 \%$ penicillin-streptomycin (Sigma), at $37^{\circ} \mathrm{C}$ with $5 \% \mathrm{CO}_{2}$ in incubator. For mitochondrial membrane potential measurement and cell viability, 1 x $10^{4}$ cells were plated in 96-well plates with DMEM 0\% FBS supplemented with 1\% penicillin-streptomycin-glutamine and without phenol red (starvation medium, Sigma) for 4-6 h. For glutathione (GSH) quantification and Western Blot, $4 \times 10^{5}$ cells were plated in 6 wells in complete medium, and at confluence, they were incubated with starvation medium overnight. For reactive oxygen species (ROS) quantification, $2.5 \times 10^{4}$ cells/well were plated in 96well. Each experimental protocol was repeated in five different cell samples.

\section{Cell viability}

Oxidative stress was generated in Huh7.5 and LX-2 through $25 \mu \mathrm{M}$ menadione for 60 min in starvation medium. Control cells were treated with DMEM 0\% FBS and phenol red only. Cell viability was examined by using the 1\% 3-[4,5-dimethylthiazol-2-yl]-2,5-diphenyl tetrazolium bromide (MTT; Life Technologies Italia, Monza, Italy) dye, as previously described [13-15]. Huh7.5 and LX-2 were treated with 60 min menadione (Sigma) alone or in the presence of genistein (10 pM; $100 \mathrm{nM} ; 1 \mu \mathrm{M})$ and $17 \beta$ estradiol $(10 \mathrm{pM} ; 10 \mathrm{nM}$; $100 \mathrm{nM}$ ) given alone or $30 \mathrm{~min}$ before menadione. In some experiments, genistein $1 \mu \mathrm{M}$ and $17 \beta$ estradiol $100 \mathrm{nM}$ were given in Huh7.5 and LX-2 pretreated for 15 min with fulvestrant $(1 \mu \mathrm{M})$ or G15 $(1 \mu \mathrm{M})$. After each treatment, the medium was removed and fresh culture medium without red phenol and FBS and with 


\section{Cellular Physiology Cell Physiol Biochem 2017;42:1051-1062 \\ \begin{tabular}{l|l} 
and Biochemistry & $\begin{array}{l}\text { DOI: 10.1159/000478752 } \\
\text { Published } 2017 \text { (c) } 2017 \text { The Author(s). Published by S. Karger AG, Basel } \\
\text { www.karger.com/cpb }\end{array}$ \\
\hline
\end{tabular} \\ Surico et al.: Cytoprotection Exerted by Estrogens and Phytoestrogens}

MTT dye was added in 96-well plates containing the cells and incubated for $2 \mathrm{~h}$ at $37^{\circ} \mathrm{C}$ in an incubator. Thereafter, the medium was removed, and an MTT solubilization solution was added and mixed in a gyratory shaker until the complete dissolution of formazan crystals. Cell viability was determined by measuring the absorbance through a spectrometer (BS1000 Spectra Count, San Jose, CA, USA).

Mitochondrial membrane potential measurement

Mitochondrial membrane potential measurement in Huh7.5 and LX-2 was performed with 5,51,6,61-tetrachloro-1,11,3,31 tetraethylbenzimidazolyl carbocyanine iodide assay. Cells were stimulated as described for cell viability. After stimulations, the medium of cells was removed and incubated with 5,51,6,61-tetrachloro-1,11,3,31 tetraethylbenzimidazolyl carbocyanine iodide 1X diluted in Assay Buffer 1X for $15 \mathrm{~min}$ at $37^{\circ} \mathrm{C}$ in an incubator following the manufacturer's instruction and as previously performed (Invitrogen, Life Technologies Europe BV, Monza, Italy) [13-15]. The red (excitation $550 \mathrm{~nm} / \mathrm{emission} 600$ $\mathrm{nm}$ ) and green (excitation $485 \mathrm{~nm} / \mathrm{emission} 535 \mathrm{~nm}$ ) fluorescence was measured using a fluorescence plate reader (BS1000 Spectra Count). To establish the cells undergoing apoptosis, the ratio of red to green fluorescence was determined and expressed as percentage.

\section{Glutathione (GSH) quantification}

In Huh7.5 and LX-2 treated with genistein $(10 \mathrm{pM} ; 100 \mathrm{nM} ; 1 \mu \mathrm{M})$ and $17 \beta$ estradiol $(10 \mathrm{pM} ; 10 \mathrm{nM}$; $100 \mathrm{nM}$ ), as described for cell viability and mitochondrial membrane potential measurement, the content of GSH was determined by using a commercial kit according to the manufacturer's instructions (Cayman, Ann Arbor, Michigan, USA) [13-15]. Briefly, $4 \times 10^{5}$ cells were lysed on ice with $2 \mathrm{ml}$ of iced-cold Glutathione Assay Buffer and a rubber policeman. Thereafter, cells were collected by centrifugation $(2000 \mathrm{~g}$ for $10 \mathrm{~min}$ at $4^{\circ} \mathrm{C}$ ), the cell pellet was homogenized in $2 \mathrm{ml}$ cold Glutathione Assay Buffer and vortexed for several seconds. After samples were centrifuged at $10,000 \mathrm{~g}$ for $15 \mathrm{~min}$ at $4^{\circ} \mathrm{C}$, the supernatant was removed and stored on ice. The supernatant was deproteinized before assaying and then $50 \mu \mathrm{L}$ of the samples was transferred to a 96-well plate where GSH was detected following the manufacturer's instructions through a spectrometer (BS1000 Spectra Count) at excitation/emission wavelengths of 340 and $420 \mathrm{nM}$. GSH content was expressed as nmol $/ 10^{5}$ cells.

\section{ROS quantification}

The oxidation of 2,7-dichlorodihydrofluorescein diacetate into 2,7- dichlorodihydrofluorescein was used to assess ROS generation, following the manufacturer's instructions (Abcam, Cambridge, United Kindom), and as previously performed $[14,15]$. Briefly, cells in 96 -well plates were stimulated with genistein $(10 \mathrm{pM} ; 1 \mu \mathrm{M})$ and $17 \beta$ estradiol (10 pM; $100 \mathrm{nM})$, as described for GSH measurement. After treatments, the reactions were stopped by removing medium and washing with phosphate buffer saline followed by staining with $10 \mu \mathrm{M} 2,7$-dichlorodihydrofluorescein diacetate for $20 \mathrm{~min}$ at $37^{\circ} \mathrm{C}$. The fluorescence intensity of 2,7-dichlorodihydrofluorescein diacetate was measured at excitation/emission wavelengths of $485 \mathrm{~nm}$ and $530 \mathrm{~nm}$ by using a spectrometer (BS1000 Spectra Count).

\section{Cell co-culture model}

To investigate whether Huh7.5 stimulated with genistein and $17 \beta$ estradiol can exert protective effects against oxidative stress in LX-2, we co-cultured LX-2 with Huh7.5 supernatants for $24 \mathrm{~h}$ in 96-well plates. For co-culture, $1 \times 10^{4}$ Huh7.5 have been seeded and stimulated with genistein $(10 \mathrm{pM} ; 100 \mathrm{nM} ; 1 \mu \mathrm{M}$ for $30 \mathrm{~min}$ ) and $17 \beta$ estradiol (10 pM; $10 \mathrm{nM} ; 100 \mathrm{nM}$ for $30 \mathrm{~min})$, alone and after 60 min pretreatment with menadione $(25 \mu \mathrm{M})$. In some samples menadione was given together with fulvestrant $(1 \mu \mathrm{M})$ or G15 (1 $\mu \mathrm{M})$. After stimulation, cells were washed with phosphate buffer saline $1 \mathrm{X}$ and after adding new DMEM $0 \%$ FBS, without phenol red for $24 \mathrm{~h}$. Then, Huh7.5 supernatants were transferred on LX-2 $\left(1 \times 10^{4}\right.$ cells seeded in 96-well plates) which have been pretreated for $60 \mathrm{~min}$ with menadione (Flowchart 1). At the end of stimulation, MTT and 5,51,6,61-tetrachloro-1,11,3,31 tetraethylbenzimidazolyl carbocyanine iodide assays were performed on LX-2 supernatants, whereas ROS was quantified in both Huh7.5 and LX-2 supernatants, as previously described. 


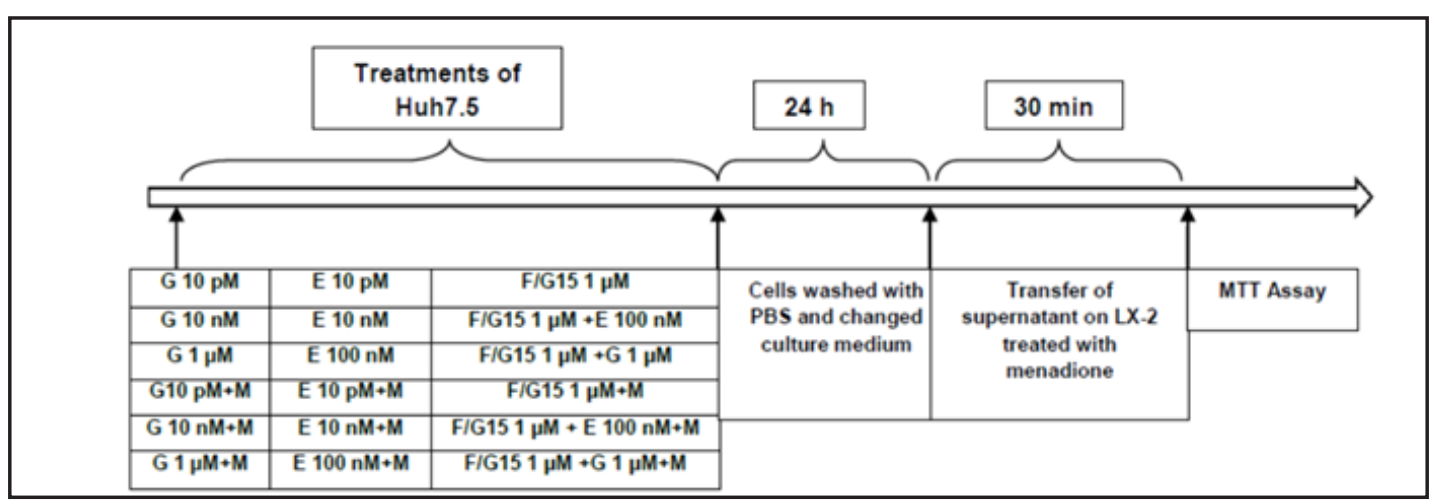

Flowchart 1. Experimental protocol followed in co-culture method of stimulation. Huh7.5 were treated with genistein (G), $17 \beta$ estradiol (E), fulvestrant (F) or G15 (G15) alone or in presence of menadione $(\mathrm{M}, 25 \mu \mathrm{M})$. Huh7.5 supernatant was transferred to LX-2 undergone menadione treatment. Thereafter, 3-[4,5-dimethylthiazol-2-yl]-2,5-diphenyl tetrazolium bromide assay (MTT) was performed on LX-2 supernatants.

\section{Cell lysates}

The LX-2 and Huh7.5 at confluence were plated in starvation medium overnight at $37^{\circ} \mathrm{C}$ with $5 \% \mathrm{CO}$. Western Blot analysis was performed on Huh7.5 and LX-2-treated with genistein ( $1 \mu \mathrm{M}$ for $30 \mathrm{~min})$ and 17 $\beta$ estradiol (100 $\mathrm{nM}$ for $30 \mathrm{~min}$ ) before menadione (25 $\mu \mathrm{M})$ administrated for $60 \mathrm{~min}$. In addition, Western Blot was performed on LX-2 co-cultured with Huh7.5, as previously described. At the end of stimulations, Huh7.5 and LX-2 were lysed in iced-Ripa-buffer supplemented with 1:200 sodium orthovanadate and 1:100 protease inhibitors cocktail and phenylmethanesulfonyl fluoride (1:100; Sigma). The extract proteins were quantified through bicinchoninic acid protein (Pierce, Rockford, IL, USA) and used for electrophoresis and immunoblotting studies [13-15].

\section{Western blotting}

Cell lysates ( $30 \mu \mathrm{g}$ protein each sample) dissolved in Laemmli buffer $5 \mathrm{x}$, boiled for 5 min were resolved in $10 \%$ sodium dodecyl sulfate polyacrylamide gel electrophoresis gels (Bio-Rad Laboratories, Hercules, CA, USA); after electrophoresis they were transferred to polyvinylidene fluoride membranes (Bio-Rad Laboratories), which were incubated overnight at $4{ }^{\circ} \mathrm{C}$ with specific primary antibodies: anti phospho-Akt (p-Akt, 1:1000; Ser473, Santa Cruz Biotechnology, Inc., CA, USA), anti phospho-p38 MAPK (p-p38MAPK, 1:1000; Thr180/Thr182, Cell Signalling Technologies, Danvers, MA, USA), $\alpha$-SMA (1:1000; Cell Signalling Technologies). The membranes were washed and then incubated with horseradish peroxidase-coupled goat anti-rabbit IgG (Sigma), peroxidase-coupled rabbit anti-goat IgG and horseradish peroxidase-coupled goat anti-mouse IgG (Sigma) for $45 \mathrm{~min}$ and were developed through a nonradioactive method using Western Lightning Chemiluminescence (PerkinElmer Life and Analytical Sciences, Waltham, MA, USA). Phosphorylated protein expression was calculated as a ratio towards $\beta$-actin (1:5000; Sigma).

\section{Statistical analysis}

All data were recorded using the Institution's database. Statistical analysis was performed by using STATVIEW version 5.0.1 for Microsoft Windows (SAS Institute Inc., Cary NC, USA). Data were checked for normality before statistical analysis. All the results obtained were examined through one-way ANOVA followed by Bonferroni post hoc tests. The non-parametric Mann Whitney $U$ test for unpaired data was used to compare percentage responses. All data are presented as means \pm standard deviation (SD) of five independent experiments for each experimental protocol. A value of $P<0.05$ was considered statistically significant.

\section{Results}

Effects of $17 \beta$ estradiol and genistein on Huh7.5

In Huh7.5 cultured in physiological conditions, $17 \beta$ estradiol and genistein improved cell viability in a dose-dependent way. As shown in Fig. 1A, both agents exerted the highest 


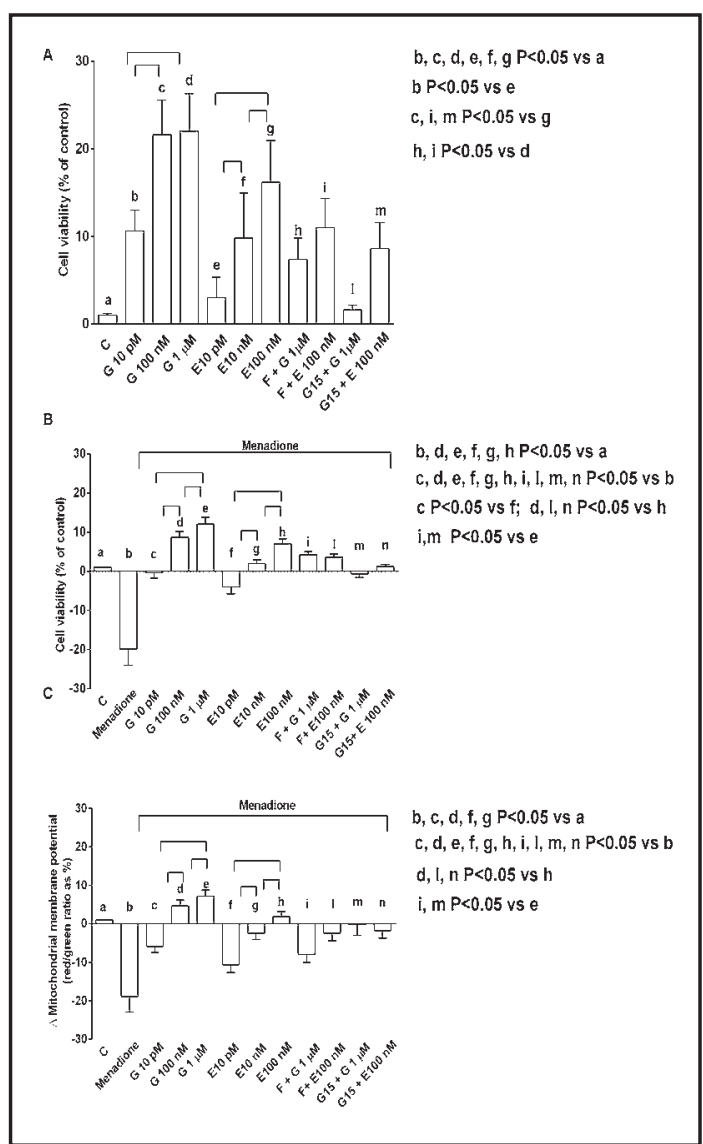

Fig. 1. Effects of genistein (G) and 17 ßestradiol (E) on Huh7.5 cell survival in physiologic/oxidative stress conditions and on mitochondrial membrane potential in oxidative stress conditions. In A, physiological conditions; in $\mathrm{B}$ and $\mathrm{C}$, oxidative stress conditions. $\mathrm{C}=$ control; F: fulvestrant $(1 \mu \mathrm{M})$; G15: G15 (1 $\mu \mathrm{M})$. Reported data are means \pm SD of five independent experiments. Short square brackets indicate significance between groups $(P<0.05)$.

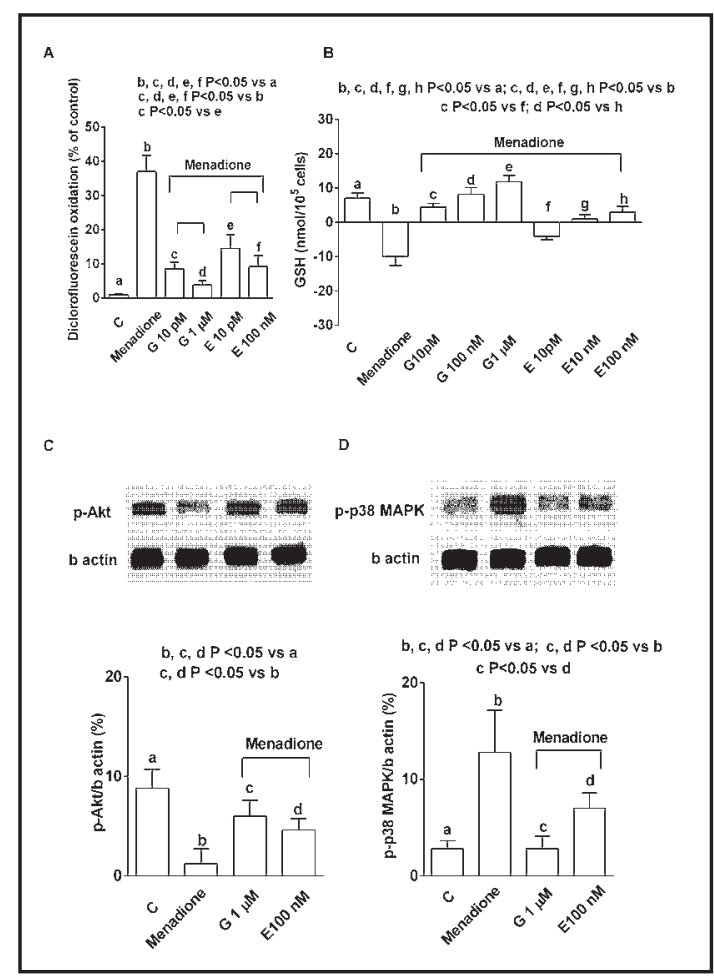

Fig. 2. Effects of genistein $(G)$ and $17 \beta$ estradiol (E) on ROS release (A), GSH content (B), Akt (C) and p38MAPK (D) activation in Huh7.5 undergone peroxidation. In $\mathrm{C}$ and $\mathrm{D}$, densitometric analysis and an example of Western Blot taken from 5 different experiments are shown. p-Akt: phosphorylated Akt; MAPK: mitogen activated protein kinases. Abbreviations are as in Fig. 1. Reported data are means \pm SD of five independent experiments. Short square brackets indicate significance between groups $(P<0.05)$.

effect at $100 \mathrm{nM}$. In addition, changes in cell viability and the loss of mitochondrial membrane potential in Huh7.5 were counteracted by $17 \beta$ estradiol and genistein. In this case, the highest effect was elicited by $1 \mu \mathrm{M}$ genistein and $100 \mathrm{nM} 17 \beta$ estradiol (Fig. 1B and 1C). Finally, both agents reduced ROS release in a dose-related way, while increasing GSH content (Fig. 2A and 2B). Also in this case, the highest effect was exerted by $1 \mu \mathrm{M}$ genistein and 100 nM $17 \beta$ estradiol.

As shown in Fig. 1A and 1B, fulvestrant and G15 were able to counteract the effects of the estrogen and the phytoestrogens on cell viability. In addition, in presence of the blockers, Huh7.5 were less protected against the reduction of mitochondrial membrane potential caused by menadione (Fig. 1C).

As described in Fig. 2C and 2D, the protective effects elicited by genistein and $17 \beta$ estradiol against peroxidation in Huh7.5 were accompanied by the keeping of Akt activation and the inhibition of p38MAPK phosphorylation.

Effects of direct treatment of LX-2 with $17 \beta$ estradiol and genistein

As shown in Fig. 3A, $17 \beta$ estradiol and genistein caused a slight increase of cell viability in LX-2 cultured in physiological conditions only at the highest doses. Moreover, in cells 


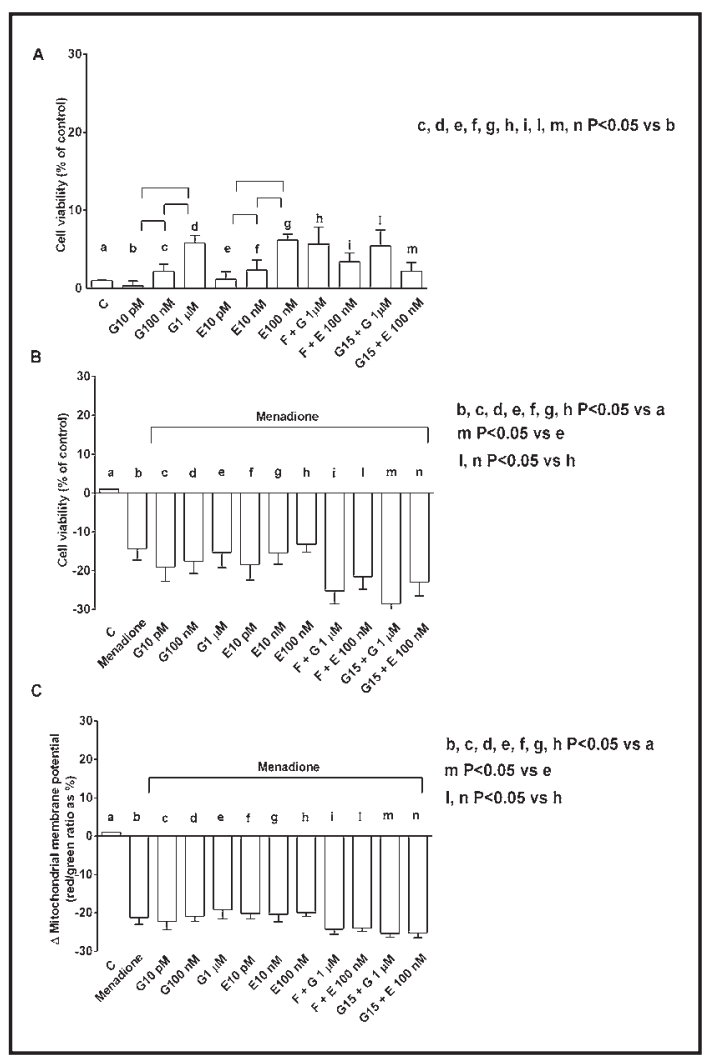

Fig. 3. Effects of genistein (G) and 17 ßestradiol (E) on LX-2 cell survival in physiologic/oxidative stress conditions and on mitochondrial membrane potential in oxidative stress conditions. In A, physiological conditions; in $\mathrm{B}$ and $\mathrm{C}$, oxidative stress conditions. Abbreviations are as in Fig. 1, 2. Reported data are means \pm SD of five independent experiments. Short square brackets indicate significance between groups $(P<0.05)$.

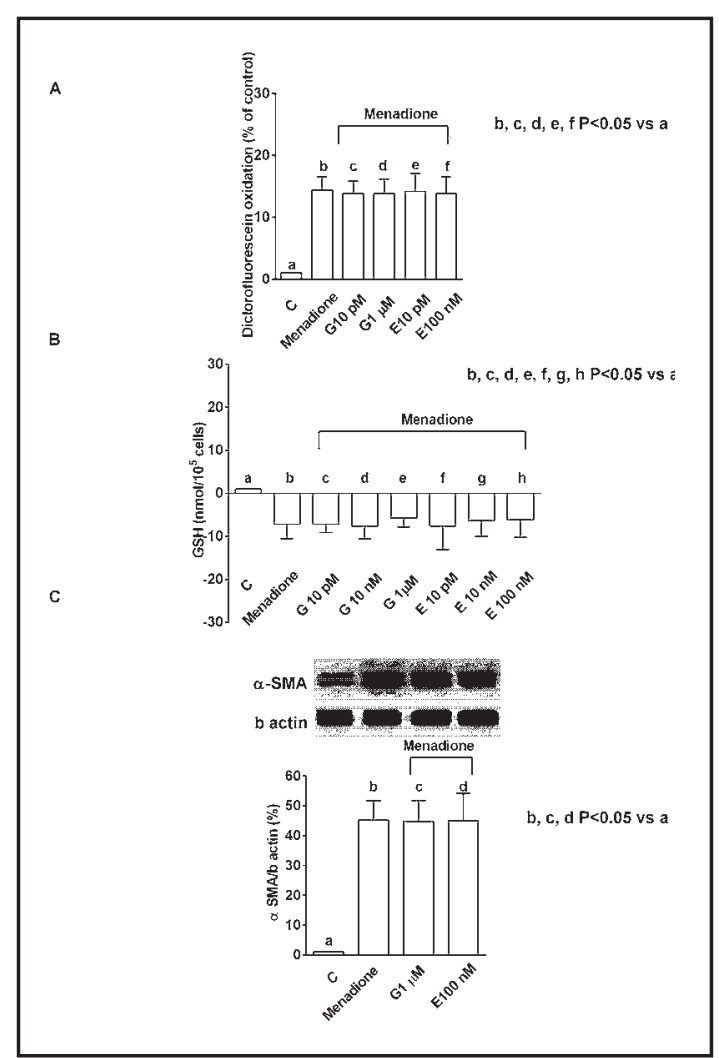

Fig. 4. Effects of genistein (G) and $17 \beta$ estradiol (E) on ROS release (A), GSH content (B), and $\alpha$-SMA expression (C) in LX-2 undergone oxidative stress. In C, densitometric analysis and an example of Western Blot taken from 5 different experiments are shown. SMA: smooth muscle actin. Other abbreviations are as in previous Fig. Reported data are means \pm SD of five independent experiments.

subjected to peroxidation, neither $17 \beta$ estradiol nor genistein were able to counteract the reduction of cell viability and of mitochondrial membrane potential caused by menadione (Fig. 3B and 3C). Those findings were accompanied by the absence of any protective effects on ROS release or GSH content and on the activation into myofibroblastic-like cells (Fig. 4AC). The blocking of ERs and GPER was able to reduce the effects of $17 \beta$ estradiol only on cell viability in physiological conditions (Fig. 3A). Moreover, in LX-2 treated with the estrogens in peroxidative conditions, fulvestrant and G15 worsened cell viability and mitochondrial membrane potential. Regarding genistein, the same finding was observed in LX-2 treated with G15 only (Fig. 3B and 3C).

Effects of co-culture of Huh7.5 and LX-2 on cell viability, mitochondrial membrane potential, and $R O S$ release

As shown in Fig. 5A, the treatment of LX-2 with the supernatants taken from Huh7.5 treated with genistein and $17 \beta$ estradiol in absence of menadione improved LX- 2 viability to a greater extent in comparison with what was observed when those agents were directly 


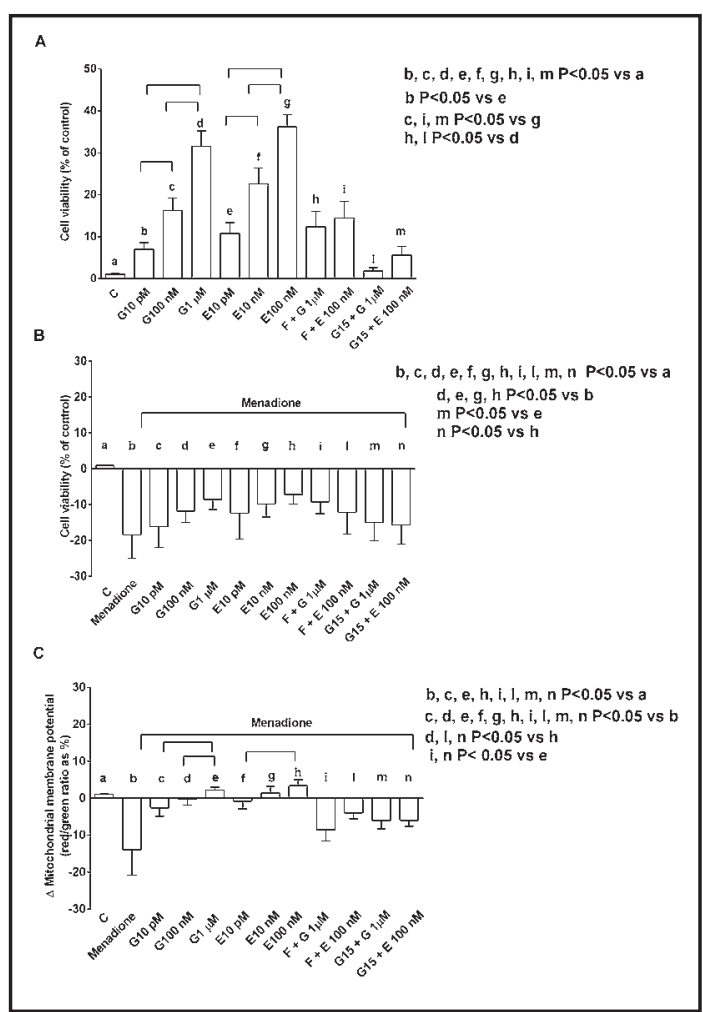

Fig. 5. Experiments of co-culture of Huh7.5 and LX2. Effects of genistein $(G)$ and $17 \beta$ estradiol (E) on LX-2 cell survival in physiological (A) and oxidative stress conditions (B) and on mitochondrial membrane potential in oxidative stress conditions (C). Abbreviations are as in previous Fig. Reported data are means \pm SD of five independent experiments. Short square brackets indicate significance between groups $(P<0.05)$.

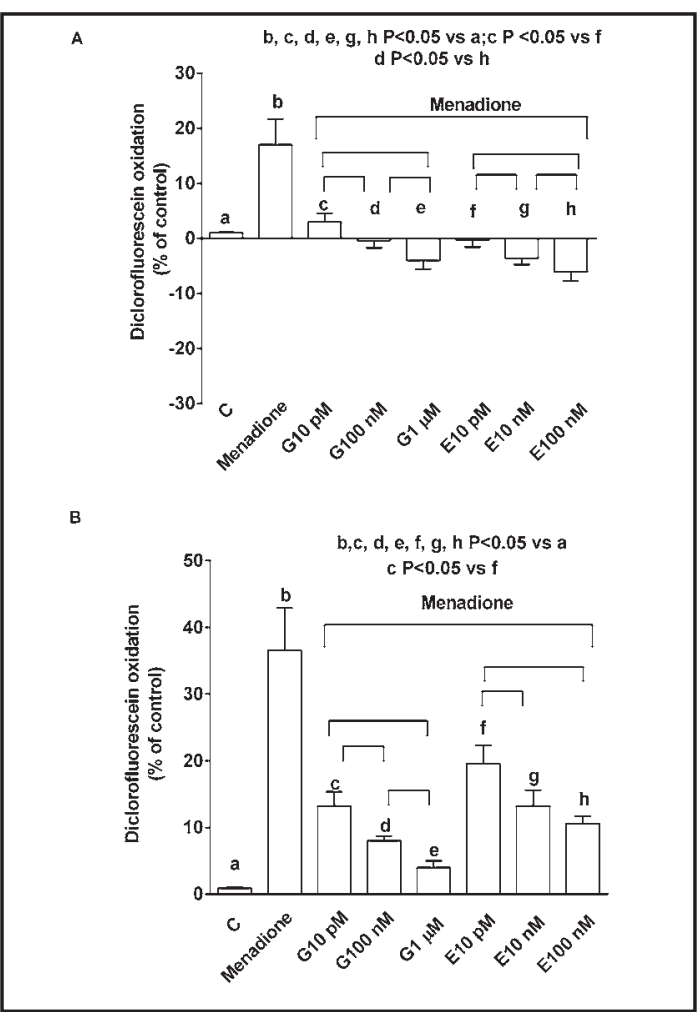

Fig. 6. ROS release by LX-2 co-cultured with Huh7.5 (A) and by Huh7.5 (B). Abbreviations and layout are as in previous Fig. Reported data are means \pm SD of five independent experiments. Short square brackets indicate significance between groups $(P<0.05)$.

administrated to LX-2. In addition, the effects on LX-2 were dose-related. Moreover, in peroxidative conditions, the supernatants of Huh7.5 treated with $17 \beta$ estradiol and genistein were able to counteract the reduction of mitochondrial membrane potential and the increase of ROS release by LX-2 (Fig. 5C and 6A). It is to note that, as previously observed, also ROS release by Huh7.5 was dose-dependently reduced by both genistein and $17 \beta$ estradiol (Fig. $6 \mathrm{~B})$. Regarding cell viability, protective effects were obtained with genistein, $100 \mathrm{nM}$ and 1 $\mu \mathrm{M}$, and $17 \beta$ estradiol, $10 \mathrm{nM}$ and $100 \mathrm{nM}$ (Fig. 5B). Hence, at those doses, genistein and $17 \beta$ estradiol were able to reduce the effects of menadione on cell viability of about $34 \%$ and $50 \%$, and $50 \%$ and $60 \%$, respectively. As shown in Fig. 5A, the treatment of Huh7.5 with both fulvestrant and G15 was able to reduce the response of LX-2 to genistein and 17 $\beta$ estradiol on cell viability in physiological conditions. Moreover, ERs and GPER blockers prevented the protection exerted by the estrogens and the phytoestrogens against the loss of mitochondrial membrane potential in LX-2 (Fig. 5C). Regarding cell viability, only G15 could worsen the response of LX-2 to genistein and $17 \beta$ estradiol (Fig. 5B).

Western Blot analysis showed that in LX-2 co-cultured with Huh7.5, both genistein and $17 \beta$ estradiol reduced $\alpha$-SMA expression, p-Akt and p 38 MAPK activation (Fig. 7). 
Fig. 7. Effects of genistein $(G)$ and $17 \beta$ estradiol (E) on $\alpha$-SMA expression (A), Akt (B) and p38MAPK activation (C) in LX-2 co-cultured with Huh7.5. In A-C, densitometric analysis and an example of Western Blot taken from 5 different experiments are shown. Abbreviations are as in previous Fig. Reported data are means \pm SD of five independent experiments.

\section{Discussion}

This study has shown for the first time that $17 \beta$ estradiol and genistein can differentially modulate cell viability in Huh7.5 and HSCs cultured in physiological or pathological conditions. While in absence of peroxidation both agents were able to increase cell viability, in Huh7.5 and in LX-2 co-cultured with Huh7.5 only $17 \beta$ estradiol and genistein prevented cell damage and the fall of mitochondrial membrane potential caused by menadione by modulating oxidant/antioxidant system.

In sustained inflammatory response ROS release from the lipid peroxidative processes can damage the parenchymal cell membranes and represents the starting

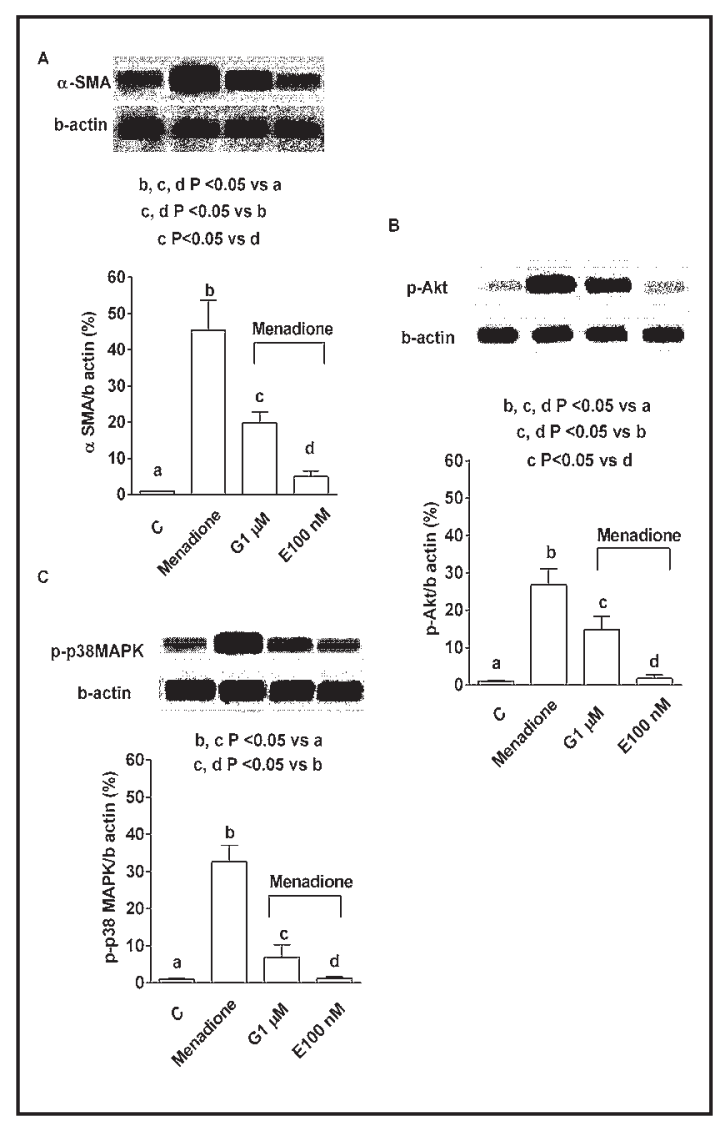
point of liver injury [16]. In this context, the balance between oxidant/antioxidant systems can play a pivotal role [17]. Although mild liver injury usually results in an almost complete resolution, persistence of the original insult causes prolonged activation of tissue repair mechanisms, leading to hepatic fibrosis. Collagen is mainly produced by HSCs, which are regarded as the primary target for inflammatory and peroxidative stimuli and are transformed into myofibroblastic-like cells, which are able to synthesize $\alpha$-SMA [18].

In our study, $17 \beta$ estradiol, was used at a concentration range, amounting to $10^{-9}$ $10^{-7} \mathrm{M}$, which can commonly be found in menstrual/menopausal women [18, 19]. Similar doses of 17-estradiol have also been previously used in both hepatic stellate cells [18] and hepatocytes [20] in studies about protection against oxidative stress.

In Huh7.5 cultured both in physiological condition and during peroxidation, $17 \beta$ estradiol was able to improve cell viability. It is to note that oxidative stress was obtained by using the intracellular generator of hydrogen peroxide, menadione, at similar concentration as the one that was able to change GSH content in hepatocytes [21]. Furthermore, the effects of $17 \beta$ estradiol were accompanied by the prevention of ROS release and the keeping of GSH content, as previously shown about antioxidant effects of estradiol in liver [22].

Also genistein exerted similar protective effects in Huh7.5 as those caused by the estrogens. It is to note that genistein was used at similar concentrations as the ones previously used in porcine aortic endothelial cells [12] and in hepatic stellate cells, where it was able to inhibit proliferation and counteract $\alpha$-SMA expression [23]. Furthermore, the chosen doses of genistein were similar to the ones of $17 \beta$ estradiol, to enable better comparison of the effects of both agents.

In our study, genistein was more effective than the estrogens in the keeping of oxidant/ antioxidant system and cell viability. Thus, our data would support the hepatoprotective role played by soybean extracts, which could be elicited through the modulation of oxidative stress $[24,25]$. 
The results obtained about mitochondrial membrane potential are of particular interest. Hence maintenance of mitochondrial function is essential for the survival and normal performance of hepatocytes, which have a high energy requirement [26]. In particular, mitochondrial depolarization can result in energy crisis and in the release of apoptotic signaling molecules, which could finally encounter cell death [27]. In Huh7.5 only, both genistein and $17 \beta$ estradiol were able to counteract the fall of mitochondrial membrane potential caused by peroxidation and to keep cell survival. Although accumulating evidence indicates that $17 \beta$ estradiol can modulate the mitochondrial function in different cell lines [28], the direct evaluation of changes of membrane potential in Huh7.5 has not yet been fully examined. Furthermore, in vivo studies have shown negative effects of exogenous 17 $\beta$ estradiol on mitochondria of ovariectomized rats [29]. Also the results obtained with genistein are quite new and in disagreement with previous ones. Hence, in isolated rat liver mitochondria genistein caused swelling, loss of membrane potential and the opening of transition pore [30]. Similar findings were obtained in human hepatocarcinoma cell lines [31].

Phosphatidylinositol-4,5-bisphosphate 3-kinase/Akt is known to be responsible for regulation of hepatocytes cell size via its downstream molecules such as mTOR in addition to being known for its survival, anti-apoptotic and anti-oxidative properties [32,33]. Moreover, in the liver the imbalance of oxidant/antioxidant system can also lead to the activation of stress-sensitive signaling pathways called MAPK $[34,35]$. It is also worth of note that in human hepatocarcinoma cell lines cells multiple membrane-starting pathways have been reported to be rapidly activated by the ER-estradiol complex and the blockade of phospholipase C/ protein kinase C, ERK, and AKT pathways completely prevented the estradiol-induced DNA synthesis.

Those intracellular signalling downstream ERs have also been proven to have a critical role in estradiol action as a survival agent [36]

In our study both $17 \beta$ estradiol and genistein were able to inhibit p38MAPK and to increase Akt phosphorylation in Huh7.5 undergone peroxidation. Those results are similar to previous findings obtained in different experimental settings [37, 38]

The findings we obtained in LX-2 were quite different from those observed in Huh7.5. Thus, it is notable that any bias related to gender differences have been avoided since both cell lines were of male human origin. In the absence of peroxidation, $17 \beta$ estradiol and genistein were able to improve cell viability only at the highest doses. Moreover, $17 \beta$ estradiol was more effective than genistein. Furthermore, in LX-2 treated with menadione at similar doses as the ones previously used in HSCs [39], either genistein or $17 \beta$ estradiol failed to protect them against the loss of cell viability and mitochondrial membrane potential and from the increased expression of $\alpha$-SMA. Those results were accompanied by the absence of any effect on oxidant/antioxidant system.

Interesting data were obtained by experiments of co-culture. In contrast to what was observed in LX-2 directly treated with $17 \beta$ estradiol and genistein, the treatment of LX-2 with the supernatants of Huh7.5 stimulated with all doses $17 \beta$ estradiol and genistein, was able to increase cell viability in physiologic conditions. Furthermore, in peroxidative conditions, mitochondrial membrane potential of LX-2 was prevented from collapse and the effects of menadione on cell viability and ROS release were reduced. Also those results were different from the ones obtained in LX-2 directly treated with estrogens and phytoestrogens under peroxidation. Moreover, those findings were accompanied by the inhibition of $\alpha$ - SMA expression and of the activation of Akt and p38MAPK, which have been reported to be involved in LX-2 myofibroblastic transformation. Thus, our findings would suggest that both Akt and p38MAPK could play a role in the intracellular pathway leading to $\alpha$-SMA inhibition in LX-2 treated with supernatants of Huh7.5 $[40,41]$. The co-culture experiments would confirm the importance of the cross talk between Huh7.5 and LX-2 in mediating liver progression towards fibrosis and in eliciting the protective effects of $17 \beta$ estradiol and genistein. Hence, differences obtained with treatment of LX-2 alone or in co-culture with Huh7.5 could be related to the role of paracrine stimuli derived from hepatocytes undergoing oxidative stress 


\section{Cellular Physiology Cell Physiol Biochem 2017;42:1051-1062 \begin{tabular}{l|l} 
DOI: 10.1159/000478752 & and Biochemistry \\
Published onnine: June 28, 2017 & $\begin{array}{l}\text { O 2017 The Author(s). Published by S. Karger AG, Basel } \\
\text { www.karger.com/cpb }\end{array}$
\end{tabular}}

Surico et al.: Cytoprotection Exerted by Estrogens and Phytoestrogens

that could modulate HSCs cell viability/mitochondrial membrane potential whilst preventing HSCs activation and collagen synthesis. In particular, and as previously reported, HSCs activation could be inhibited by Huh7.5 through the reduction of peroxidative stimuli. Thus, the finding of our study showing a low tendency of LX-2 to mutate into myofibroblastic-like cells could be related to the reduction of ROS release by Huh7.5 treated with $17 \beta$ estradiol and genistein. Furthermore, the comparison of the results obtained in various experimental protocols involving LX-2 would highlight the importance of the keeping of mitochondrial membrane potential for preventing their activation. Hence, while in LX-2 undergone direct administration of genistein or $17 \beta$ estradiol the collapse of mitochondrial membrane potential was not counteracted and $\alpha$-SMA was not inhibited, the opposite was observed in co-culture experiments.

The effects of estrogens on the liver have been reported to be related to the ER subtypes, $\mathrm{ER} \alpha$ and ER $\beta$ [16]. Furthermore, one non-classical mechanism of $17 \beta$ estradiol action is through the involvement of GPER [9], which can be predominantly found in the membrane of the endoplasmic reticulum.

Although not fully examined, our findings would suggest that both receptors could be involved in the modulation of the response to the estrogens and the phytoestrogen in both Huh7.5 and LX-2. Hence, although in the liver ER $\alpha$ has been reported to be the more expressed form, hepatocytes and HSCs were proven to possess more functional ER $\beta$ than ER $\alpha[2,42,43]$. In our study, the blocking of ERs and GPER in Huh7.5 and LX-2 was able to reduce or abolish the effects of both $17 \beta$ estradiol and genistein. Those findings are in line with previous observations showing the abolishment of protective effects elicited by either $17 \beta$ estradiol or genistein in the liver [22].

Although not clearly examined, our findings would also highlight the involvement of both MAPK and Akt in the intracellular mechanisms downstream ERs activation by either 17 $\beta$ estradiol or genistein in Huh7.5 and LX-2. Those data would be in agreement with previous reports about the mechanisms of action of those agents [2, 9-12, 43].

However, further experiments will be needed to address the rate ER $\beta / E R \alpha$ expression/ activation in Huh7.5 and LX-2 and the related intracellular signalling and to examine their crosstalk with GPER signaling [44].

In conclusion, this study has shown that $17 \beta$ estradiol and genistein can differently exert protection against oxidative injuries in Huh7.5 and LX-2 by either direct actions or through the modulation of a cross talk between those cell lines. Those effects would be related to both ERs and GPER. Finally, our findings would support clinical observations about the different evolution of hepatic fibrosis in postmenopausal women or men versus premenopausal women and about the delay that hormone replacement therapy with estrogen would cause cirrhosis evolution in postmenopausal women $[2,5,45]$.

\section{Acknowledgement}

We thank Azienda Ospedaliero-Universitaria of Novara for its help.

\section{Disclosure Statement}

The authors declare that there is no conflict of interests regarding the publication of this article.

\section{References}

1 Chen Y, Dong H, Thompson DC, Shertzer HG, Nebert DW, Vasiliou V: Glutathione defense mechanism in liver injury: Insights from animal models. Food Chem Toxicol 2013;60:38-44.

2 Shimizu I: Impact of oestrogens on the progression of liver disease. Liver Int 2003;23:63-69. 


\section{Cellular Physiology Cell Physiol Biochem 2017;42:1051-1062 \begin{tabular}{l|l} 
and Biochemistry Published onlıne: June 28, 2017 & $\begin{array}{l}\text { (c) } 2017 \text { The Author(s). Published by S. Karger AG, Basel } \\
\text { www.karger.com/cpb }\end{array}$
\end{tabular}}

3 Li S, Tan HY, Wang N, Zhang ZJ, Lao L, Wong CW, Feng Y: The role of oxidative stress and antioxidants in liver diseases. Int J Mol Sci 2015;16:26087-26124.

-4 Brady CW: Liver disease in menopause. World J Gastroenterol 2015;21:7613-7620.

-5 Borrás C, Gambini J, López-Grueso R, Pallardó FV, Viña J: Direct antioxidant and protective effect of estradiol on isolated mitochondria. Biochim Biophys Acta 2010;1802:205-211.

6 Serejo F, Emerit I, Filipe PM, Fernandes AC, Costa MA, Freitas JP, de Moura MC: Oxidative stress in chronic hepatitis C: the effect of interferon therapy and correlation with pathological features. Can J Gastroenterol 2003;17:644-650.

7 Di Martino V, Lebray P, Myers RP, Pannier E, Paradis V, Charlotte F, Moussalli J, Thabut D, Buffet C, Poynard T: Progression of liver fibrosis in women infected with hepatitis C: long-term benefit of estrogen exposure. Hepatology 2004;40:1426-1433.

8 Susutlertpanya W, Werawatganon D, Siriviriyakul P, Klaikeaw N: Genistein attenuates nonalcoholic steatohepatitis and increases hepatic PPAR $\gamma$ in a rat model. Evid Based Complement Alternat Med 2015;2015:509057.

-9 Ulitzky L, Lafer MM, KuKuruga MA, Silberstein E, Cehan N, Taylor DR: A new signaling pathway for hcv inhibition by estrogen: GPR30 activation leads to cleavage of occludin by MMP-9. PLoS One 2016;11:e0145212.

10 Joy S, Siow RC, Rowlands DJ, Becker M, Wyatt AW, Aaronson PI, Coen CW, Kallo I, Jacob R, Mann GE: The isoflavone Equol mediates rapid vascular relaxation: $\mathrm{Ca} 2+-$ independent activation of endothelial nitricoxide synthase/Hsp90 involving ERK1/2 and Akt phosphorylation in human endothelial cells. J Biol Chem 2006;281:27335-27345.

11 Cheng D, Zhang L, Yang G, Zhao L, Peng F, Tian Y, Xiao X, Chung RT, Gong G: Hepatitis C virus NS5A drives a PTEN-PI3K/Akt feedback loop to support cell survival. Liver Int 2015;35:1682-1691.

12 Grossini E, Molinari C, Mary DA, Uberti F, Caimmi PP, Surico N, Vacca G: Intracoronary genistein acutely increases coronary blood flow in anesthetized pigs through beta-adrenergic mediated nitric oxide release and estrogenic receptors. Endocrinology 2008;149:2678-2687.

13 Surico D, Farruggio S, Marotta P, Raina G, Mary D, Surico N, Vacca G, Grossini E: Human chorionic gonadotropin protects vascular endothelial cells from oxidative stress by apoptosis inhibition, cell survival signalling activation and mitochondrial function protection. Cell Physiol Biochem 2015;36:2108-2120.

14 Grossini E, Bellofatto K, Farruggio S, Sigaudo L, Marotta P, Raina G, De Giuli V, Mary D, Pollesello P, Minisini R, Pirisi M, Vacca G: Levosimendan inhibits peroxidation in hepatocytes by modulating apoptosis/ autophagy interplay. PLoS One 2015;10:e0124742.

15 Grossini E, Gramaglia C, Farruggio S, Bellofatto K, Anchisi C, Mary D, Vacca G, Zeppegno P: Asenapine increases nitric oxide release and protects porcine coronary artery endothelial cells against peroxidation. Vascul Pharmacol 2014;60:127-141.

16 Shimizu I, Kohno N, Tamaki K, Shono M, Huang HW, He JH, Yao DF: Female hepatology: favorable role of estrogen in chronic liver disease with hepatitis B virus infection. World J Gastroenterol 2007;13:42954305.

17 Poli G: Pathogenesis of liver fibrosis: role of oxidative stress. Mol Aspects Med 2000;21:49-98.

- 18 Itagaki T, Shimizu I, Cheng X, Yuan Y, Oshio A, Tamaki K, Fukuno H, Honda H, Okamura Y, Ito S: Opposing effects of oestradiol and progesterone on intracellular pathways and activation processes in the oxidative stress induced activation of cultured rat hepatic stellate cells. Gut 2005;54:1782-1789.

19 White MM, Zamudio S, Stevens T, Tyler R, Lindenfeld J, Leslie K, Moore LG: Estrogen, progesterone, and vascular reactivity: potential cellular mechanisms. Endocr Rev 1995;16:739-751.

20 Liu Y, Shimizu I, Omoya T, Ito S, Gu XS, Zuo J: Protective effect of estradiol on hepatocytic oxidative damage World J Gastroenterol 2002;8:363-366.

-21 Sentellas S, Morales-Ibanez 0, Zanuy M, Alberti JJ: GSSG/GSH ratios in cryopreserved rat and human hepatocytes as a biomarker for drug induced oxidative stress. Toxicol in Vitro 2014;28:1006-1015.

22 Omoya T, Shimizu I, Zhou Y, Okamura Y, Inoue H, Lu G, Itonaga M, Honda H, Nomura M, Ito S: Effects of idoxifene and estradiol on NF-kappaB activation in cultured rat hepatocytes undergoing oxidative stress. Liver 2001;21:183-191.

23 Liu XJ, Yang L, Mao YQ, Wang Q, Huang MH, Wang YP, Wu HB: Effects of the tyrosine protein kinase inhibitor genistein on the proliferation, activation of cultured rat hepatic stellate cells. World J Gastroenterol 2002;8:739-745.

24 Susutlertpanya W, Werawatganon D, Siriviriyakul P, Klaikeaw N: Genistein attenuates nonalcoholic steatohepatitis and increases hepatic PPAR $\gamma$ in a rat model. Evid Based Complement Alternat Med 


\section{Cellular Physiology Cell Physiol Biochem 2017;42:1051-1062 \begin{tabular}{l|l|l} 
and Biochemistry & $\begin{array}{l}\text { DOI: 10.1159/000478752 } \\
\text { Published onlIne: June 28, } 2017\end{array}$ & $\begin{array}{l}\text { C) } 2017 \text { The Author(s). Published by S. Karger AG, Basel } \\
\text { www.karger.com/cpb }\end{array}$
\end{tabular}}

2015:509057.

-25 Kim EY, Hong KB, Suh HJ, Choi HS: Protective effects of germinated and fermented soybean extract against tert-butyl hydroperoxide-induced hepatotoxicity in HepG2 cells and in rats. Food Funct 2015;6:3512-3521.

-26 Cervinková Z, Lotková H, Kriváková P, Rousar T, Kucera O, Tichý L, Cervinka M, Drahota Z: Evaluation of mitochondrial function in isolated rat hepatocytes and mitochondria during oxidative stress. Altern Lab Anim 2007;35:353-361.

27 Taziki S, Sattari MR, Dastmalchi S, Eghbal MA: Cytoprotective Effects of Melatonin Against AmitriptylineInduced Toxicity in Isolated Rat Hepatocytes. Adv Pharm Bull 2015;5:329-334.

28 Chen JQ, Yager JD, Russo J: Regulation of mitochondrial respiratory chain structure and function by estrogens/estrogen receptors and potential physiological/pathophysiological implications. Biochim Biophys Acta 2005;1746:1-1717.

29 Moreira PI, Custódio JB, Nunes E, Moreno A, Seiça R, Oliveira CR, Santos MS: Estradiol affects liver mitochondrial function in ovariectomized and tamoxifen-treated ovariectomized female rats. Toxicol Appl Pharmacol 2007;221:102-110.

-30 Salvi M, Brunati AM, Clari G, Toninello A: Interaction of genistein with the mitochondrial electron transport chain results in opening of the membrane transition pore. Biochim Biophys Acta 2002;1556:187-196.

- 31 Jiang H, Ma Y, Chen X, Pan S, Sun B, Krissansen GW, Sun X: Genistein synergizes with arsenic trioxide to suppress human hepatocellular carcinoma. Cancer Sci 2010;101:975-983.

-32 Fujiyoshi M, Ozaki M: Molecular mechanisms of liver regeneration and protection for treatment of liver dysfunction and diseases. J Hepatobiliary Pancreat Sci 2011;18:13-22.

-33 Wan ZY, Tian JS, Tan HW, Chow AL, Sim AY, Ban KH2, Long YC: Mechanistic target of rapamycin complex 1 is an essential mediator of metabolic and mitogenic effects of fibroblast growth factor 19 in hepatoma cells. Hepatology 2016;64:1289-1301.

34 Chen Z, Li YX, Fu HJ, Ren YL, Zou L, Shen SZ, Chen P, Sun T, Huang CH: Hepatitis B Virus Core Antigen Stimulates IL-6 Expression via p38, ERK and NF- $\kappa$ B Pathways in Hepatocytes. Cell Physiol Biochem 2017;41:91-100.

35 Son Y, Kim S, Chung HT, Pae HO: Reactive oxygen species in the activation of MAP kinases. Methods Enzymol 2013;528:27-48.

-36 Marino M, Galluzzo P, Ascenzi P. Estrogen signaling multiple pathways to impact gene transcription. Curr Genomics 2006;7:497-508.

- 37 Yang X, Qin L, Liu J, Tian L, Qian H: 17ß-Estradiol protects the liver against cold ischemia/reperfusion injury through the Akt kinase pathway. J Surg Res 2012;178:996-1002.

-38 Ganai AA, Khan AA, Malik ZA, Farooqi H: Genistein modulates the expression of NF- $\kappa$ B and MAPK (p-38 and ERK1/2), thereby attenuating d-Galactosamine induced fulminant hepatic failure in Wistar rats. Toxicol Appl Pharmacol 2015;283:139-46.

-39 Dunning S, Hannivoort RA, de Boer JF, Buist-Homan M, Faber KN, Moshage H: Superoxide anions and hydrogen peroxide inhibit proliferation of activated rat stellate cells and induce different modes of cell death. Liver Int 2009;29:922-932.

-40 Wang H, Zhang H, Zhang Y, Wang D, Cheng X, Yang F, Zhang Q, Xue Z, Li Y, Zhang L, Yang L, Miao G, Li D, Guan Z, Da Y, Yao Z, Gao F, Qiao L, Kong L, Zhang R: Plumbagin protects liver against fulminant hepatic failure and chronic liver fibrosis via inhibiting inflammation and collagen production. Oncotarget DOI:10.18632/oncotarget.12655.

- 41 Ikeda R, Ishii K, Hoshikawa Y, Azumi J, Arakaki Y, Yasui T, Matsuura S, Matsumi Y, Kono Y, Mizuta Y, Kurimasa A, Hisatome I, Friedman SL, Kawasaki H, Shiota G: Reactive oxygen species and NADPH oxidase 4 induced by transforming growth factor $\beta 1$ are the therapeutic targets of polyenylphosphatidylcholine in the suppression of human hepatic stellate cell activation. Inflamm Res 2011;60:597-604.

42 Miyashita T, Toyoda Y, Tsuneyama K, Fukami T, Nakajima M, Yokoi T: Hepatoprotective effect of tamoxifen on steatosis and non-alcoholic steatohepatitis in mouse models. J Toxicol Sci 2012;37:931-942.

-43 Zhou Y, Shimizu I, Lu G, Itonaga M, Okamura Y, Shono M, Honda H, Inoue S, Muramatsu M, Ito S: Hepatic stellate cells contain the functional estrogen receptor beta but not the estrogen receptor alpha in male and female rats. Biochem Biophys Res Commun 2001;286:1059-1065.

44 Barton M: Position paper: The membrane estrogen receptor GPER--Clues and questions. Steroids 2012;77:935-942.

45 Magri A, Barbaglia MN, Foglia CZ, Boccato E, Burlone ME, Cole S, Giarda P, Grossini E, Patel AH, Minisini R, Pirisi M: 17, $\beta$-estradiol inhibits hepatitis $C$ virus mainly by interference with the release phase of its life cycle. Liver Int DOI:10.1111/liv.13303. 